\title{
Engineering as a process of Beauty
}

Book or Report Section

Accepted Version

Ewart, I. J. (2018) Engineering as a process of Beauty. In: Bunn, S. (ed.) Anthropology and Beauty: From Aesthetics to Creativity. Routledge. ISBN 9781138928794 Available at http://centaur.reading.ac.uk/67447/

It is advisable to refer to the publisher's version if you intend to cite from the work. See Guidance on citing.

Publisher: Routledge

All outputs in CentAUR are protected by Intellectual Property Rights law, including copyright law. Copyright and IPR is retained by the creators or other copyright holders. Terms and conditions for use of this material are defined in the End User Agreement.

www.reading.ac.uk/centaur 
Central Archive at the University of Reading

Reading's research outputs online 


\section{Engineering as a Process of Beauty}

\section{Seeing Production}

Anthropological writing has historically explored perceptions of beauty as an aesthetic response to a physical object, stemming perhaps from the discipline's early links with collections of exotic curios and ethnographic museums (e.g. Phillips 1998). The fundamentally aesthetic approach to objects can be seen in Morphy and Perkins' excellent compilation of essays (Morphy and Perkins 2007), which shows how anthropology rejoices in objects as caricatures of culture, and has done so since the century before last. But look carefully among the pages about representation and symbolism, style and form, and you may be lucky enough to take in the chapter by David Guss, 'All Things Made' (ibid: 374-386), which goes some way to bringing in the act of making to a bookful of gazing and thinking (see also Guss 1990). Fortunately there have been a number of scholars who have recently engaged in projects to bring production to the fore, including notably Ingold (e.g. 2013) and Marchand (2009; 2016), although they are severely outgunned by the aesthetes so I add here my own modest reinforcement. With a specific focus on engineering, my aim in this chapter is to suggest that the act of production is beautiful, as much as the artefacts that are made; that there is a sense of beauty in the care and effort of production, as well as, or even instead of, a visual pleasure. To an engineer, workmanship trumps aesthetics.

The goal of engineering is to make something that works. This may or may not be at the expense of its attractiveness, but the physical appearance of the artefact is determined to a large extent by the constraints of the necessary function. Size and shape are determined by the space available and the stresses of operation; combinations of materials chosen for their physical properties; production made efficient through the use of appropriate tools, and so on. Where engineering has to satisfy the twin roles of functioning mechanism and attractive object this usually results in compromise or disguise. As Don Norman tells us, the iconic Philippe Starck lemon juicer on the cover of his book (Norman 2004) does not actually work very well, and some editions actually come with a warning not to use them for squeezing lemons at all, as the surface would be damaged by the acidic juice! On a larger scale, Tower Bridge in London is iconic for its faux-gothic brickwork, no more than a decorative façade intended to conceal the magnificent and monstrous Victorian industrial engineering that raises and lowers the bascule drawbridge (Cruickshank 2010: 297-8). Even the monumental beauty of the Clifton suspension bridge is not all it seems. Brunel's original design was half as big again, but rejected as unbuildable by Thomas Telford, the design competition judge. Telford's own subsequent suggestion was rejected as being too ugly. The design finally chosen, from Brunel, had to be stripped of its Egyptian-esque ornamentation during construction as money 
ran out, and the bridge eventually stumbled to completion after Brunel had died (Cruickshank 2010: 239-43). In these examples and in many others, the popular notion of beauty in engineering is related uncompromisingly to the aesthetics of the resulting artefact, and not the process of production and workmanship.

To explore the notion of engineering as a process of beauty, the example I use is that of a team of volunteer engineers restoring a steam locomotive, and a description of the work that went into producing a set of bespoke copper lubrication pipes. Admittedly quite an esoteric choice, but that is the point: to most people, bent copper tubes hold limited attraction, and yet their function - moving oil from one part of a machine to another - can be easily understood and appreciated. Engineering is literally and essentially functional, and the primary goal of an engineered part is not its form but its purpose; in engineering there is less sentiment for artistry than workmanship. Of course engineers themselves are not insensitive to aesthetics, but there is a particular engineering sense of beauty that responds to the work required to produce something well. So my suggestion is that an affinity for engineering generates an appreciation of beauty through empathy for the work of production, rather than a response to the visual aesthetics of the engineered artefact.

\section{Ugly Engineering}

In the news recently there has been a great deal of attention on space exploration, with remarkable pictures coming back from Mars, Pluto and even from the surface of a comet. As achievements in engineering these are undoubtedly of the highest order, and yet the machines that have given us these pictures are not usually referred to in terms of their attractiveness - they are not what one might call 'beautiful' in the usual sense of the word. Freed from the constraints of gravity and air resistance, they have no need to follow the organic principles that Norman describes as offering visceral attractiveness (Norman 2004). On planet Earth, whether on land, in the air, or under water, moving objects have to contend with the forces associated with friction and gravity, which we try to overcome with ingenious solutions (quite often by blatantly copying nature). Streamlined shapes and limited contact with the ground make some things possible and everything else more efficient, but in space these rules do not apply, there is no air resistance to hinder flying objects, and there are no naturally evolved shapes for the designers to copy. Since the cost of getting space objects into their environment is literally astronomical, the defining criteria are size and weight. Small and light objects can be economically feasible, without a specific need to attend to their external appearance. The appearance of the object is a by-product of the various functions that are necessary to make it work: solar panels, instrumentation, data-gathering devices, protection and so on. And usually with such a complex and expensive engineering project, responsibilities are divided among international 
teams, each of whom will produce a specific instrument or function. The final artefact ends up being shaped according to functional principles and political compromises between the various parties involved, producing a package of parts that does not need a coherent or defining visual framework. When you see a satellite being assembled by teams dressed from tip to toe in disposable overalls, it looks ungainly and confusing, with skinny pieces of metal poking out in all directions and shiny gold-covered sections next to a confusing mass of exposed wiring and collapsed solar panels (Figure 1). The only allusion to beauty seems to be in the remarkable pictures of distant worlds that they beam back.

And yet in interviews with the engineers, they would often describe the satellite itself as beautiful. So what are they seeing, what scales of judgement are they applying? Beauty, the saying goes, is in the eye of the beholder. Perhaps, as with any parent describing their own child, the satellite engineers have a biased view. Or perhaps the aesthetics per se are not the most significant factor in ascribing beauty to the object; there is some other sense of beauty they are experiencing, a sense of pride in production, an understanding of the effort and difficulties that underlay the process.

Of course I am not the first to suggest that encountering an object can elicit an emotional response. The art world lives on that very principle, which allowed Gell, in his anthropology of art, to demonstrate the need for studies of material culture to move away from the focus on what things mean to the effect things have on us. The classic example is his description of 'enchantment' (Gell, in Hirsch ed. 2006: 159-186) where his intention was to "wrest the anthropological study of artworks away from the soggy embrace of philosophical aesthetics" (ibid: 17). For Gell, an art object had the ability to 'enchant' if it fell outside the boundaries of experience of the casual observer, who is rendered unable to comprehend the techniques and skill of the maker. The artist may even deliberately demonstrate her technical prowess by executing her artistry in ways that are beyond the experience of everyday folk, like an illusionist performing an apparently impossible trick. Conversely, when seen by a knowledgeable observer, able to recognize the subtleties of the work, the parts that are truly innovative or difficult, the same object still elicits a sense of admiration and respect. This may go some way to explaining why an engineer, looking on a complex piece of work such as an 'ugly' satellite might see it as beautiful. The use of the word beautiful might be in reference to something other than the object's appearance, more a way of offering a respectful nod to the producers, recognizing the workmanship and dedication as much as the finished object itself. 
Here, I need to extend Gell's enchantment idea, since he explicitly says that "art objects are the only objects around which are beautifully made, or made beautiful" (ibid: 163). He is making the distinction between things that occur naturally, such as sunsets or people, and things that have been made as products of techniques. The veracity of such a distinction, between natural things and made things, is of course questionable, since any boundaries are blurred and contextual, if they exist at all (Ingold 2013). Such a broad definition of art seems to want to lay claim to all kinds of things, including for example, the cattle groomed and dressed by the Sudanese Dinka, the subject of a debate with Jeremy Coote (see Gell 2006: 215-231). He refutes the contention made by Coote that these cattle are a product of a Dinka visual aesthetic governed by their immediate environment: a 'marvel of everyday vision'. The cattle are man-made (by oiling, horn shaping, decoration etc.) but with a social objective in mind - to provide their owners with a forum for competitive performance of poetry and display, to increase their social prestige. Gell says that what is chosen to be appreciated is contingent on the social milieu, and might have been very different: "It always turns out that if people want things to look one way rather than another, it is for reasons which cannot be stated in terms of just how things look" (ibid: 231). However, to draw such close ties between the deliberate production of objects to be beautiful, and the consequent emphasis on their aesthetics is quite restrictive. We might say that not all art objects are either beautiful or beautifully-made, or conversely that not all beautifully-made objects are art, either for the producer or the observer. So I come back to the question I raised earlier, when looking at ugly engineering, how can it still be beautiful?

\section{Knowledgeable Observation}

We can see the 'marvels of everyday vision' debate as more than just a discussion of sensory aesthetics, since both sides to the argument begin with a similar contention, which is that to understand what is seen as beautiful depends on an understanding of what it means to be beautiful. For Coote, the beauty of Dinka cattle comes from an ongoing cultural engagement with the environment, and for Gell the artist's corpus, including the cattle, poems and performances, are carefully presented in an act of political gamesmanship. The common theme is knowledgeable behaviour as the underpinning notion of beauty: doing the right things, and doing them well, is what is being lauded and not just the aesthetic consequences.

In the first half of 2015, the British Museum exhibited a collection of ancient Greek art under the title "Defining beauty: the body in ancient Greek art" (Jenkins 2015). This was a collection of artistic representations of the human body, offering an insight into the classical Greek enthusiasm for idealized beauty. In the exhibition, Socrates is quoted as saying "In portraying ideal types of 
beauty... you bring together from many models the most beautiful features of each". So although these sculptures are realistic in the sense that they look like a human body, they are idealized in that they are not what one would expect to have seen walking the streets of Athens 2500 years ago. However, to the ancient Greeks, the idealism represented in these sculptures was not simply visual, since the achievement of a body beautiful was seen as the manifestation of a morally upstanding life.

In classical Greece the notion of kalon, usually translated as 'beautiful', merges two apparently distinct ideas: beauty and morality. For Plato and Aristotle in particular, the links between the aesthetics of an object and its virtue are difficult to untangle. Aryeh Kosman, a renowned scholar of classical Greece, quotes Aristotle in saying that "lives marked by the virtue of courage and by virtue in general are to be sought after in order that such lives should exhibit beauty" (2010: 342). Although kalon is not used to describe the wonders of nature, neither is it a direct equivalent to our notion of artistic beauty, as in the beauty of an object. It is more closely associated with what we might call 'admirable' and specifically how something admirable is manifested. In Plato's Hippias Major, the usefulness of objects is part of their kalon, as well as their ability to bring joy (ibid), so there is a sense that for something to be seen as beautiful, it must fulfil a worthy purpose, and do so well, a sentiment rejuvenated by the UK 'Arts and Crafts Movement' and especially William Morris in the late $19^{\text {th }}$ century (Coleman 1988). Any object however humble, whether a wooden spoon, or in the case of the British Museum exhibition a human body, is seen as beautiful not for its aesthetic appeal, but as proof of an idealized purpose. The achievement of a body beautiful was a manifestation of a life well-lived, a life abiding by the classical Greek ideal of desire informed by reason: we desire appropriately and then act on those desires (Kosman 2010:356).

The use of one word, kalon, to mean both something that is beautiful and something that is morally good presents something of a philosophical puzzle. It seems to suggest that either all beautiful things are virtuous and moral, or that one who is able to recognize beauty can similarly recognize what it is to be moral. This is not an idea restricted to classical Greece however, Kant has also famously written of the sensations of beauty and their association with personality traits in his 'Observations on the feeling of the beautiful and sublime (1764)' (in Frierson and Guyer (eds.) 2011). Kant discussed two similar 'finer feelings', for the beautiful and for the sublime, which he considered to be distinct from both higher intellectual feelings and lower basic feelings. An intermediate feeling, such as for the beautiful or the sublime, was a "sensuous feeling of which the more common souls are also capable", but was nonetheless "fit for virtuous impulses, or because it is a sign of talents and excellences of the intellect" (Frierson and Guyer 2011:14). He suggests that 
these feelings are created by both the thing being observed - the beauty of a sunset, or the nobility of a mighty oak - and also by the character of the observer. His ideas for exactly what those characteristics are seem archaic in a modern context, such as his use of the four human temperaments (melancholic, sanguine, choleric and phlegmatic); the outrageously sexist Third Section (a woman who strives to overcome "laborious learning or painful grubbing, even if a woman could get very far with them...might as well also wear a beard” (2011:36-7)); or xenophobic Fourth Section on national characteristics ("Holland can be regarded as the land where this finer taste is fairly unnoticeable" (2011:50)). However, we are in no more a position to judge Kant's $18^{\text {th }}$ century social attitudes than we are able to see our own absurdities, and so it would be foolish to dismiss the crux of his argument on that basis. He is to some extent agreeing with the Greek notion of the observation of beauty, or the sublime, requiring appropriate understanding. For the ancient Greeks, it was an understanding of moral living, and in $18^{\text {th }}$ century Germany it was an appreciation of intellect and social standing.

Where Kant differs from the ancient Greek notion of kalon, is in his efforts to separate out the decorative or adorned (beauty) from the noble or admirable (sublime). As we have seen, scholars of ancient Greek have struggled to agree on how to interpret kalon, simply because it merges these feelings and beliefs into a single concept. The space satellite might satisfy the ideology of kalon, as a product of exemplary behaviour (i.e. good engineering), and provide Kant with an example of the sublime, but would struggle to fulfil his criteria for the beautiful. But what is missing from Kant's philosophical musings about these 'finer feelings', is any feeling created through or by the process of production, unlike the Greek appreciation for living and growing in a moral way. Whether beautiful or sublime, his various examples of the sight of a mountain, the prospect of a meadow, the description of a storm or Milton's depiction of hell, a comedy or tragedy, even the Egyptian Pyramids or St. Peter's in Rome, all of these are visualizations, either literal or metaphorical. There is no sense of the beauty of the process that went into their production or growth (which it has been argued are in fact one and the same, e.g. Ingold 2011). The feeling generated by observing the beautiful is one that comes from a snapshot experience, a fleeting moment in time, lacking the process of becoming. Missing from the 'prospect of a meadow' is the population of flowers with their pollination, seasonal growth, bursting into colour, going to seed and dying back. Or the thought and practice, writing and rehearsals that go into producing a comedy, whether formally on the stage or informally as a dinner table anecdote. By observing the Great Pyramids, as an ideal example of sublimity, surely it is blindingly obvious that our admiration is, to a great extent, of their process of production, and not simply of the aesthetics of large geometric shapes?! Of course I am not suggesting that it is not possible to appreciate beauty 'in the moment', or only through an 
understanding of the growth or production of that which is observed, but I am suggesting that the process of becoming is generative of feelings of beauty, especially in those with appropriate understanding.

\section{The Didcot Railway Centre}

To illustrate this suggestion of beauty as inherent in production, I want to turn to the idea of something 'well-engineered'. There is a popular understanding of what that might mean, by relating to a feeling of quality and robustness, but to an engineer there are further subtleties such as ingenuity, simplicity and an understanding of difficulty. Most of the objects that we encounter are not of course Gell's 'art objects', that we might judge according to our personal measure of beauty; most objects are consumer products, marketed to persuade us into ascribing them with higher value than their production might deserve. They are all 'engineered', even if we are unaware of the extent or method of engineering that has gone into them, and through general familiarity, we might feel able to pass judgement to some degree on whether the object is 'well-made'. Of course our judgement can always be called into question, and even manipulated by the producer to create an illusion of quality - adding weight, for example, even if that is unnecessary, or with clever packaging. For an engineer, whose task is to overcoming practical problems with simple and yet ingenious solutions, there is a sense of 'good engineering' that does not necessarily relate to those illusory tactile or visual cues offered in a consumer product. So for my example, I will keep as far away as possible from the worlds of art and consumerism, and stick to traditional engineering. I will draw on my experiences as a volunteer at the Didcot Railway Centre, helping in the restoration and resurrection of a steam locomotive: engine number 6023 'King Edward II' (Figure 2). I will also base some of my observations and assertions on many years spent as an industrial engineer.

The Didcot Railway Centre is a surprisingly large site, hidden away behind the mainline railway station of an anonymous town in southern England. If Didcot is famous then it is for one of two things: the large power station with its imposing cooling towers, until recently visible for many miles (sadly these icons of industrial architecture are in the process of demolition) and the town's links to the Great Western Railway (the local football team are known as 'the Railwaymen' in homage to the historic importance of the railway to Didcot). Lying roughly at the intersection of the east-west routes between London and Bristol (and onwards to America), and the north-south routes between the south-coast ports and the traditional industrial heartlands of England, Didcot was established as a railway town in the 1840s. Although the history of the UK's railway is turbulent, convoluted and fraught with political interference, and not something to be covered in any detail here, a few key facts are useful to set the scene. After leading the world in the development of 
steam technology from the early 19th century, the UK railway system grew rapidly until, by the 1930s a plethora of local operators had been absorbed into the so-called 'big-four' regional rail companies, including the Great Western Railway (GWR). Co-ordination between the big-four during WW2 demonstrated the advantages of a single national rail system, which, along with increasing competition from road transport, resulted in the creation of British Railways (BR) in 1948. There followed a series of ill-planned modernization attempts, including a hasty move away from steam power to the more modern diesel and electric engines, all of which served only to illustrate how cumbersome the rail network was. Ultimately the infamous 'Reshaping of British Railways Report' of 1963 by Dr. Beeching signaled the final demise of steam power along with the closure of half of the stations and one third of the track (Whitehouse and St. John-Thomas 2002). The last scheduled BR service powered by steam ran in August 1968, by which time most of the stock of steam engines had been decommissioned and sent to scrapyards where they were stripped for parts or cut up for scrap metal (Figure 3).

At the same time, around the country groups of steam enthusiasts were clubbing together to buy up and maintain old steam locomotives. The Great Western Society, formed in 1967 was one such group, taking over the Didcot locomotive depot, closed in 1965 as part of the Beeching cuts, to form the Didcot Railway Centre (DRC) with the intention of saving the heritage of the GWR. Today, the DRC houses an impressive collection of GWR locomotives, some active rail track, a museum and education centre. At the heart of the site is the large 1930s engine shed, where maintenance and restoration takes place, carried out by teams of volunteers, and where a 'King' class locomotive, No. 6023 'King Edward II', went through a substantial rebuild and restoration.

As with most steam locomotives, 6023 had been worked hard. Commissioned in 1930, it ran over 1.5 million miles between London and the west of England until it was condemned in 1962. It had a complex maintenance history, with many of its major components being replaced several times - it had thirteen different boilers during its working life - along with a series of repairs and upgrades. Unusually, 6023 was retained by BR post-Beeching, tethered to its sibling, engine 6024 'King Edward I', the two engines formed a deadweight used to test the strength of bridges until 1980. So although it escaped the initial purge and destruction of steam locomotives in the 1970s, when it reached the scrapyard it was rapidly stripped to feed the many restorations of other GWR locomotives by then underway. When it ended up at the DRC in 1995 for restoration it was in a sorry state of disrepair and eventually took over 20 years to bring back to life.

\section{The Morality of Good Engineering}


Large parts of 6023 had to be sourced or re-manufactured, as far as possible according to the original drawings from the 1930s, still available from the archives of the GWR. This was made especially challenging as many of the tools and techniques had been lost in the intervening years. One of the large driving wheels had been cut away and had to be re-cast, the first time this had been done in over 40 years, using a specification of steel that was no longer available, and machined on equipment that had also long been decommissioned. To make the whole job more difficult, the team of volunteer engineers had set themselves the goal of making 6023 'mainline-ready'. In other words this would be a steam locomotive that could be used on the national rail network and not just be restricted to heritage rail lines. Modern electronic safety systems had to be incorporated, and the height of the driver's cab and chimneys lowered by 4 inches. The engineers made strenuous efforts to disguise these changes, hiding the electronics out of view in the cab, using existing control levers instead of modern switchgear, carefully shaping new bodywork and so on. Any work done on the project was done in the spirit of the original, even though virtually all of the machine was either new, borrowed, or changed.

This causes a perennial problem for restorers of steam locomotives, treading a fine line between recreating something that can be considered truly authentic, and yet having to rely on a whole range of re-worked or modern replacement parts and materials. In the heritage railway industry this can fall foul of the self-appointed guardians of authenticity - so-called 'rivet counters' - who will check every detail of a restoration down to the last detail, such as the number of rivets holding two pieces of metal together. Furthermore, the recent nostalgia surrounding steam locomotives has created a new milieu in which the engineers have to work: they are no longer the technological marvels of the 1930s, the workhorses of the 1950s, or the scrap metal of the 1970s, now they represent an idealized past, a jealously guarded icon of a 'golden age'. However, the engineers on 6023 were more concerned with authentic engineering practices than ultimate authenticity of appearance, and especially a sense that they were respecting the engineering that had gone into 6023 through its construction and subsequent maintenance.

Much of the work was carried out at weekends by a core team of about 8 , many of whom were experienced in restoration, including some who owned their own steam locomotives. The work was roughly divided according to experience, where some of the more technical tasks were taken on by the more experienced engineers, and the simpler tasks went to people like me with little or no specific experience. So I spent many hours rubbing down paintwork and following instructions as best I could, while my colleagues took on the more technically difficult tasks. One such task, requiring great skill and patience, was the replacement of extensive runs of copper and steel tubing. 
These had been almost entirely stripped from 6023 following decommissioning since they were inherently valuable because of their raw material. As was common in engineering in the 1930s, when 6023 was originally made, quite large parts of the production process were left to the skills and experience of the individual engineers, and the installation of most of the tubing was one of them. The GWR was in fact a pioneer of component standardization, so that the same part could be used in different engine types, but still, some parts were bespoke to each individual engine and not necessarily drawn in great detail.

Pipes on a steam locomotive have a number of purposes, including carrying steam to and from the engine, and distributing lubricating oil to all of the moving parts. The lubrication system consisted of a reservoir, a mechanical lubricator and a series of delivery pipes, running from the lubricator to the dozens of lubricating points around the machine. The route of the tubes is convoluted, wending their way around the complex inner workings of chassis and running gear, for distances of several metres with numerous joints and bends along the way (Figure 4). Although 30 of these King class locomotives were manufactured at GWR's Swindon works, along with another 171 of their parent design the Castle class, and 73 of the similar Star class, each was individual, and the development of interchangeable parts, put in place by GWR in the 1920s, did not extend to the copper tubing for the lubrication system. So each piece of each copper tube had to be custom-made to fit around the many obstacles between the mechanical lubricator and the lubricating point. In total this meant hundreds of pieces of tubing, each bent individually into complex three dimensional shapes, fitted and checked, re-bent, re-fitted and checked again until it was an accurate fit. Virtually none of this system is visible, since it is hidden by the bodywork and metalwork of the engine, and yet the engineers carrying out this task were concerned with the standard and accuracy of every bend in every part of every tube. To some extent this is understandable and necessary, since a failure in the lubrication system could result in a catastrophic failure of a moving part of the machine with possibly dire consequences. However, the quality of workmanship went well above what was necessary to produce a functioning and robust system.

Copper tubing is still widely used in, for example, domestic central heating systems, and tools are available for plumbers to quickly and easily bend it to shape. However, our volunteer engineers did not bend their tubes like this. Instead, they produced a series of wooden jigs, heated the section of tube to red hot with a gas blowtorch, then whilst still red hot, the tube would be bent around the jig and cooled in water (Figure 5). The subsequent bend was then put in place and inspected for its fit. Where the shape did not meet the approval of the engineer, the tube would be removed and adjusted by heating and bending until the fit was correct. This procedure was repeated for each of the 
multitude of copper lubrication pipes and the larger steel steam pipes, all hand-made to fit into, through, and around specific spaces in the chassis of the engine. To understand the complexities and perseverance needed to finish this job, it is worth noting that when these locomotives were being produced by GWR in the 1930s, an entire locomotive would have been produced in about 2 months; on 6023 , this piping work alone took two men 18 months to complete.

\section{Engineering as a Process of Beauty}

So, what is the relationship between bending pipes and beauty? Copper tubing falls outside conventional aesthetic measures since it is primarily functional and its form is dictated to a large extent by the needs of that function: lubricating oil needs to be transferred from point $\mathrm{A}$ (the mechanical lubricator) to point B (the moving part that should not wear out). And constraints in the shaping of lubrication pipes are significant. Copper piping is expensive, hence its absence from 6023 when rescued, so the route must be as short as possible to keep costs to a minimum, especially considering the limited finances of heritage railway restoration. There are also good engineering and design reasons to dictate the path of the copper pipe: increasing the length introduces pressure losses through friction, so shorter is better; tight bends are less efficient than gentle curves; lubricant viscosity (the 'thickness' of the oil) needs to be predictable but is affected by heat (warm oil is 'thinner' than cold oil), so close proximity to hot parts needs to be avoided; pipes must avoid the many moving parts that could cause damage, and so on. Given all these constraints, the resulting set of copper lubricating pipes can only have a limited number of final forms, they can only 'look' a certain number of ways; this is not a blank canvas for artistic expression. Indeed the final look, one would think, is largely irrelevant, since it will be essentially invisible, buried deep inside the machine, a minor component of a much larger entity. The aesthetic of the steam locomotive lies not in its components - the shape of copper lubricating pipes weaving their way around the chassis - but in its entire size and shape, its sounds and smells, the emotions it evokes.

And yet, looking at this particular copper piping one can appreciate the work that has gone into it. The accurate lengths, parallel bends and even-splay of sets of pipes as they leave the mechanical lubricating box all speak to a degree of care and attention that was not strictly necessary. Contained within those objects are the manifestation of considered and skillful engineering. Choices were made to decide the best route; the brutal heat of a gas blow torch controlled to soften the copper until it was just pliable enough to bend; careful hand-bending around home-made wooden jigs; checking, re-heating and trying again. The engineers doing the work were not artists or even artisans, despite the fact that their accumulated skills made the routing decisions and shaping of pipes more or less second nature over time. They were making no particular concessions to the way 
they did their work, and their intention was not particularly to produce an artefact that would be considered beautiful in the sense of an object to be looked at and admired. However, it was clear that they felt responsible for their work, which they knew played a small part in the way the locomotive would function, but greater than that was the feeling that the quality of their work was also representative of the engineering standards set by the team of volunteers. Regardless as to whether or not any individual bend in the pipe was ever noticed, there remained a depth of commitment to good engineering.

Good engineering is an activity of beauty. In the same way as we have seen classical Greek notions of beauty being entwined with notions of idealized, virtuous behaviour, and the context of beautiful Dinka cattle as a cultural production process, so for something to be 'well-engineered' depends on a beautiful process. That is to say, even though an engineer looking at the copper piping may see it as beautiful, he is not seeing a secret aesthetic, hidden from the general population, but is rather seeing the act of production as beautiful, he is seeing something well-engineered. This is not enchantment, in Gell's sense of bemusement at magical skills, but recognition of perfectly secular dedication, skill and cultural understanding, and the objects are proof of that commitment to a process of beauty. Note that I am saying it is the process that is the act of beauty, and not that the resultant object has been beautified. Nor am I saying that the physical movements of the engineers when bending the tubes is analogous to a beautiful dance. Unlike a dance performance or an art object, this was not intended to be aesthetically pleasing for the observer and by most measures, lubrication systems, however carefully made, are not particularly beautiful. But for the engineers who were responsible for the copper lubrication pipes of 6023, there is beauty in the production experience, and to the knowledgeable observer the quality of engineering is recognisable in the objects. The beauty is in what they did, and not what they produced.

\section{References}

Coleman, R. 1988. The art of work. London: Pluto

Cruickshank, D. 2010. Bridges: Heroic designs that change the world. London: Collins.

Frierson, P. and Guyer, P. (eds.) 2011. Immanuel Kant: Observations on the feeling of the beautiful and the sublime and other writings. Cambridge: Cambridge University Press.

Guss, D.M. 1990. To weave and sing: Art, symbol and narrative in the South American rainforest. Berkeley: University of California Press.

Hirsch, E. (ed.) 2006. The art of anthropology: Essays and diagrams by Alfred Gell. Oxford: Berg. Ingold, T. 2011. Being alive: Essays on movement, knowledge and description. Abingdon:

Routledge 
Ingold, T. 2013. Making: Anthropology, archaeology, art and architecture. London and New York: Routledge.

Jenkins, I. 2015. Defining beauty: the body in ancient Greek art. London: British Museum Press. Kosman, A. 2010. Beauty and the Good: Situating the Kalon. Classical Philology 105(4): 341-357. Marchand, T.H.J. 2009. The masons of Djenné. Bloomington and Indianapolis: Indiana University Press.

Marchand, T.H.J. (ed.) 2016. Craftwork as problem solving: Ethnographic studies of design and making. Farnham: Ashgate.

Morphy, H. and Perkins, M. (eds.) 2007. The Anthropology of Art: a reader. Oxford: Blackwell. Norman, D.A. 2004. Emotional design: Why we love (or hate) everyday things. New York: Basic Books.

Phillips, R.B. 1998. Trading Identities: Souvenir in native North American art form the northeast, 1700-1900.Washington: Washington University Press.

Whitehouse, P. and St. John-Thomas, D. (eds.) 2002. The Great Western Railway: 150 glorious years. Newton Abbot: David and Charles.

Figure 1: Satellite under construction (courtesy of NASA)

Figure 2: GWR locomotive 6023 'King Edward II' (courtesy of www.6023.co.uk)

Figure 3: 6023 in the Woodham bros. scrapyard, c.1980 (courtesy of www.6023.co.uk)

Figure 4: Part of the 6023 lubrication system (author's photo)

Figure 5: Heating steam tubing ready for bending into shape (courtesy of www.6023.co.uk) 